\title{
XANTHOGRANULOMATOUS OOPHORITIS : A CASE REPORT
}

\section{Dr. Amrita Prasad}

Dr. Aravind.K.R.*
Senior Resident, Department of General Surgery, Rajendra Institute of Medical Sciences, Ranchi, Jharkhand.

Junior resident, M.S. General Surgery, Rajendra Institute of Medical Sciences, Ranchi, Jharkhand. * Corresponding author

ABSTRACT Xanthogranulomatous inflammation is a rare type of granulomatous inflammation and the cause is yet to be identified. In this pathology, the affected organ undergoes lysis and is replaced by dense inflammatory cell infiltrates. Here is a case of a 42 year old woman presenting with lower abdominal lump and pain for 3 months, clinical examination revealed a suspicion of tubo-ovarian mass, which on further hematological and radiological examination gave the impression of an ovarian neoplasm. Finally Histopathological study of the resected specimen came out as Xanthogranulomatous oophoritis (XO).

KEYWORDS : : Xanthogranulomatous oophoritis, ovarian neoplasm, xanthoma cells, granuloma.

\section{INTRODUCTION:}

Xanthogranulomatous inflammation is an uncommon, chronic and benign type of granulomatous inflammation. It commonly involves gall bladder and kidney. Other organs involved are stomach, anorectal area, bone, testis, epididymis. It is confined to the uterine endometrium in relevance to female genital tract. Ovarian involvement is a very rare type with $<30$ cases reported so far in the English literature. The average age of the patients was found to be 30 . The etiology is not yet identified. It cannot be diagnosed easily pre-op as it presents with a vague abdominal pain and adnexal mass. This diagnosis is purely a histopathological diagnosis rather than a clinical entity. This type of inflammation is characterized by a massive infiltration of the tissues by lipid-laden histiocytes admixed with lymphocytes, plasma cells and polymorphonuclear leukocytes. Multinucleated giant cells may also be present.

\section{CASE PRESENTATION:}

A 40 year old female presented in our surgical OPD with complaints of lower abdominal lump (Fig.1) and dull aching abdominal pain for the past 3 months. There is no history of fever, trauma, loss of appetite or loss of weight. Bladder and bowel habits found to be normal. Menstrual history was normal.

Hematological analysis such as complete blood count, renal and liver function tests were also normal except for an elevated ESR of $70 \mathrm{~mm} / \mathrm{hr}$. Serum tumor markers such as Betahcg, AFP and LDH were within normal limits, thus ruling out any genital malignancy. Routine urine examination did not reveal anything specific.

Abdominal Ultrasonography suggested Serous Cystadeno ma $\left(17.5^{*} 13.9 \mathrm{cms}\right)$ with bilateral pelvicalyceal system dilatation. Further contrast enhanced CT scan showed a thin smooth walled, well defined mass arising from pelvis extending upto the umbilical region with bilateral Hydroureteronephrosis suggestive of a right ovarian lesion $\left(20.2^{*} 13.5^{*} 17.5 \mathrm{cms}\right)$.

The patient was planned for an exploratory laparotomy which showed a cystic mass in the right adnexa of approximately $20^{*} 15 \mathrm{cms}$ size. Around $2-2.5$ litres of mucopurulent fluid was aspirated followed by entoto resection of the cyst. The cyst wall and aspirated fluid were sent for histopathological analysis.

The Histopathological report suggested of a solid, yellowish brown necrotic material enclosed in a cyst cavity. On microscopic examination, foamy histiocytes (xanthoma cells) intermixed with lymphocytes, multinucleated giant cells and plasma cells was seen which of suggestive of Xanthogran ulomatous Oophoritis. (Fig.2)
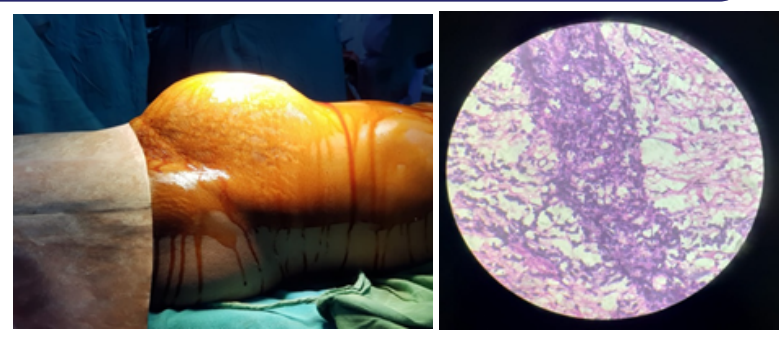

Fig 1

Fig 2

\section{DISCUSSION:}

Xanthogranulomatous Oophoritis is a form of chronic oophoritis whose etiology is unknown. The risk factors include recurrent pelvic inflammatory disease, Intrauterine device usage, abnormality in lipid metabolism, leiomyoma and endometriosis. ${ }^{(2)}$

Stewart had accounted that the xanthomatous lesions were concomitant with hypercholesterolemia. Those xanthomas associated with hyperlipidemic states are reactive lesions, wherein lipid accumulation is derived from plasma.

The most accepted theory is the presence of infection. There was a reported case of xanthogranulomatous oophoriits along with salphingitis as a late sequelae of inadequately treated Staphylococcal pelvic inflammatory disease. ${ }^{(3)}$ The most common organisms isolated from the culture of infected tissue are Escherichia coli, Staphylococcus aureus, Bacteroides fragilis and Proteus vulgaris.

The clinical presentation is variable and non specific and it requires a multi modality approach to reach this diagnosis. CT and USG most often suggests an ovarian neoplasm. Few documented magnetic resonance imaging findings in such cases include nonenhancing intramural nodules inside the thickened wall of an ovarian cystic mass. ${ }^{(4)}$

This process eventually results in replacement of the organ tissue by abundant xanthoma cells, granuloma formation, dense proliferation of fibrin and collagen deposition leading to destruction (Liquefactive Necrosis). Another important component is hemorrhagic foci.

The differential diagnosis includes Malakoplakia, Tuberculos is/fungal infections, ovarian neoplasm, tubo-ovarian abscess, secondary leukemia/lymphoma.

\section{CONCLUSION:}

As Xanthogranulomatous oophoritis (XO) has similar presenting features as that of ovarian neoplasm proper 
evaluation has to be done primarily to prevent radical surgery for the patient. This is a big diagnostic challenge for clinicians as the clinicoradiological presentation mostly mimics malignancy. Hence a diagnosis of XO has to be kept in mind when the clinical radiological and hematological reports have no co-relation.

\section{REFERENCES}

1. Gami N, Mundhra R, Guleria K, Arora VK, Garg S. Recurrent pyometra and xanthogranulomatous salpingitis: A rare pathologic association in a postmenopausal lady. J Mid-life Health 2014;5:156-8. https://doi.org/ 10.4103/0976-7800.141227 PMID:25317003.

2. Son J, Raetskaya-Solntseva O, Tirman PA, Waters GS, Kelly MG. Xanthogranulomatous oophoritis presenting as an adnexal mass and bowel obstruction: A case report. J Reprod Med 2015;60(5-6):273.

3. Punia RS, Aggarwal R, Amanjit, Mohan H. Xanthogranulomatous oophoritis and salpingitis: late sequelae of inadequately treated staphylococcal PID. Indian J Pathol Microbiol 2003;46:80.

4. Jung SE, Lee JM, Lee KY, Han KT, Hahn ST. Xanthogranulomatous oophoritis: MR imaging findings with pathologic correlation. AJR Am J Roentgenol $2002 ; 178: 749$. 